\title{
Electronic momentary assessment in chronic pain II: pain and psychological pain responses as predictors of pain disability
}

Citation for published version (APA):

Sorbi, M. J., Peters, M. L., Kruise, D. A., Maas, C. J., Kerssens, J. J., Verhaak, P. F., \& Bensing, J. M. (2006). Electronic momentary assessment in chronic pain II: pain and psychological pain responses as predictors of pain disability. Clinical Journal of Pain, 22, 67-81.

https://doi.org/10.1097/01.ajp.0000148625.84874.48

Document status and date:

Published: 01/01/2006

DOI:

10.1097/01.ajp.0000148625.84874.48

Document Version:

Publisher's PDF, also known as Version of record

\section{Document license:}

Taverne

Please check the document version of this publication:

- A submitted manuscript is the version of the article upon submission and before peer-review. There can be important differences between the submitted version and the official published version of record.

People interested in the research are advised to contact the author for the final version of the publication, or visit the DOI to the publisher's website.

- The final author version and the galley proof are versions of the publication after peer review.

- The final published version features the final layout of the paper including the volume, issue and page numbers.

Link to publication

\footnotetext{
General rights rights.

- You may freely distribute the URL identifying the publication in the public portal. please follow below link for the End User Agreement:

www.umlib.nl/taverne-license

Take down policy

If you believe that this document breaches copyright please contact us at:

repository@maastrichtuniversity.nl

providing details and we will investigate your claim.
}

Copyright and moral rights for the publications made accessible in the public portal are retained by the authors and/or other copyright owners and it is a condition of accessing publications that users recognise and abide by the legal requirements associated with these

- Users may download and print one copy of any publication from the public portal for the purpose of private study or research.

- You may not further distribute the material or use it for any profit-making activity or commercial gain

If the publication is distributed under the terms of Article $25 \mathrm{fa}$ of the Dutch Copyright Act, indicated by the "Taverne" license above, 


\title{
Electronic Momentary Assessment in Chronic Pain I: Psychological Pain Responses as Predictors of Pain Intensity
}

\author{
Marjolijn J. Sorbi, PhD, * Madelon L. Peters, PhD, † Dieta A. Kruise, MSc, * \\ Cora J. M. Maas, PhD, $\neq$ Jan J. Kerssens, PhD, $\S$ \\ Peter F. M. Verhaak, PhD, $\S$ and Jozien M. Bensing, PhD* ${ }^{*}$
}

\begin{abstract}
Objectives and Methods: Electronic momentary assessment was employed to substantiate the relevance of psychological functioning in chronic pain. More than 7100 electronic diaries from 80 patients with varying IASP classified types of chronic pain served to investigate to what extent fear-avoidance, cognitive and spousal solicitous and punishing pain responses explained fluctuations in pain intensity and whether patients with pre-chronic, recently chronic and persistently chronic pain differed in this regard.
\end{abstract}

Results: Psychological pain responses explained $40 \%$ of the total variance in pain intensity: almost $24 \%$ concerned pain variance that occurred between the CPD patients and $16 \%$ pertained to pain variance due to momentary differences within these patients. Separately tested fear-avoidance and cognitive responses each explained about $28 \%$ of the total pain variance, while spousal responses explained $9 \%$. Catastrophizing emerged as the strongest pain predictor, followed by pain-related fear and bodily vigilance. Results did not differ with the duration of chronicity.

Discussion: Exaggerated negative interpretations of pain, and fear that movement will induce or increase pain strongly predicted CPD pain intensity. Spousal responses - assessed only when the spouse was with the patient who at that moment was in actual pain-may more strongly affect immobility due to pain than pain intensity per se (see part II of the study). The findings substantiate the importance of catastrophizing, fear and vigilance identified primarily in low back pain and extend this to other forms of chronic pain. The compelling evidence of momentary within-patients differences underscores that these must be accounted for in chronic pain research and practice.

Received for publication August 8, 2001; revised June 9, 2003 and August 18, 2004; accepted October 2, 2004

From the *Department of Health Psychology, Utrecht University, Utrecht, The Netherlands, †Department of Medical, Clinical and Experimental Psychology, University of Maastricht, Maastricht, The Netherlands, \$Department of Methodology and Statistics, Utrecht University, Utrecht, The Netherlands, and §Netherlands Institute of Primary Health Care, Utrecht, The Netherlands.

Supported by the Netherlands Organisation for Scientific Research grant \#940-31-033.

Reprints: Marjolijn J. Sorbi, PhD, Department of Health Psychology, Utrecht University, P.O. Box 80 140, Utrecht 3508 TC, The Netherlands (e-mail: M.Sorbi@fss.uu.nl).

Copyright ( 2005 by Lippincott Williams \& Wilkins
Key Words: chronic pain disorder, electronic diary, pain intensity, pain duration, psychological pain predictors

(Clin J Pain 2006;22:55-66)

\section{INTRODUCTION}

\section{Focus of the Study}

According to the International Association for the Study of Pain (IASP), chronic pain is pain that persists beyond the "normal time of healing." 1 The search is thus for factors that push pain beyond normal recovery. Psychologic responses to pain are important in the development of a chronic pain disorder (CPD). ${ }^{2}$ Associations are complex, however, and it is difficult to capture these accurately and adequately. Accuracy requires fine-knit real-time measures because pain and responses to pain are fluctuating states. Retrospective report (usually applied) and real-time reports (relatively new in pain research) simply are not equivalent and recall biases the retrospective assessment of the severity, frequency, and other aspects of pain. ${ }^{3}$ Adequacy ideally requires longitudinal research covering pain from its onset through the first 6 months when CPD is established and following it through the first years of existence.

Our study aims to substantiate the association between psychological responses and, respectively, pain intensity, and disability in CPD on the basis of actual and real-time measurements. The second aim is to test whether these associations differ in the persistently chronic ( $>12$ months), recently chronic (6-12 months), and prechronic (3-6 months) phases of CPD development. The present part I of the study is directed at the psychological prediction of pain intensity and at potential differences induced by pain duration in these predictions. Part II, presented in a second paper, covers the same issues with regard to CPD disability.

\section{Psychological Responses in Chronic Pain}

Psychological responses relevant to CPD spring from cognitive and behavior theory, ${ }^{4,5}$ which distinguish fearavoidance, cognitive, and spousal pain responses. Fearavoidance pertains to actual and anticipated pain and refers to fear-induced avoidance of movements or physical activities. Pain-related fear, the apprehension that mobility will increase 
pain or bring on physical damage, ${ }^{6}$ relates to pain intensity ${ }^{7,8}$ and was found to be more disabling than pain itself in the case of chronic back pain. ${ }^{9}$ Dependent on this fear, though, enhanced attention to pain and other somatosensory symptoms also impacts on pain intensity, ${ }^{10,11}$ and the relevance of vigilance to pain and bodily sensations was confirmed by experimental studies of attention and perception in patients with chronic pain. ${ }^{12,13}$ Avoidance of mobility can be adaptive to ease recovery in acute pain. In chronic pain, however, persistent avoidance behavior is counterproductive in that it promotes muscular deconditioning and disability. ${ }^{9,14-16}$ Fearavoidance develops under the influence of cognitive learning and behavior conditioning. ${ }^{6,17-19}$

Cognitive learning shapes suffering, the cognitiveaffective dimension of chronic pain proposed by Loeser, ${ }^{20}$ and fear and worry may well be at the core of it. Maladaptive cognitive responses are thought to aggravate the suffering and influence pain behavior in CPD. Catastrophizing, the exaggerated negative interpretation of pain, was proposed as a major determinant of fear-avoidance. ${ }^{6}$ Its association with pain intensity was repeatedly ascertained ${ }^{21-25}$ and recently established with respect to pain vigilance. ${ }^{26}$ Other cognitive responses associated with pain intensity are negative selfstatements, ${ }^{27}$ hopelessness-helplessness ${ }^{28}$ (for a review, see Jensen et $\mathrm{al}^{29}$ ), and lack of control over the pain. ${ }^{30}$

Behavior conditioning has an impact primarily on pain expressions that include moaning, grimacing, motor behaviors, and help seeking. Such expressions constitute another dimension - that of pain behavior - in CPD. ${ }^{20}$ It elicits strong responses from others and can come under the control of reinforcing consequences. ${ }^{31}$ Family, particularly the spouse, may show understanding and discourage active behavior, and this may inadvertently maintain the patients' pain behavior. ${ }^{32}$ Thus, spousal solicitous and punishing responses are considered relevant in CPD. According to ample experimental evidence, solicitous reinforcement of pain behavior is positively related to pain report in healthy patients ${ }^{33-35}$ and in patients with chronic pain, ${ }^{36-43}$ whereas the opposite occurred with punishment of pain behavior, defined as "passive positive spousal reinforcement" or "low spousal solicitude." 38,39,42 Reinforcement of well behavior was less studied but shown to increase actual walking speed in chronic pain. ${ }^{44}$

\section{Methods Matter}

We wanted to follow patients with chronic pain in their daily life and derive from these data the extent to which psychological pain responses and, respectively, pain intensity and disability are associated. We employed the "experience sampling method" (ESM, ${ }^{45-47}$ a conceptual strategy similar to "ecological momentary assessment" $\left(\mathrm{EMA}^{48}\right)$ and other selfmonitoring methods, which presently are central to health psychological research on intraindividual processes over time. ${ }^{49}$ These methods come as close as it gets to in vivo observation and are defined by 3 characteristics ${ }^{3,45}$ : first, patients are studied in their natural or home environment. Second, real-time data are collected, which may be controlled by preprogrammed signals, provided by a pager, wristwatch, or palmtop computer (signal-contingent recording). Third, multiple momentary or near immediate assessments are sampled. The premise is that momentary occasions are rooted in a particular context and that experiences are best characterized by a representative sample of such moments. As others have noted, the method "focuses attention on sampling of moments as an important component of design validity, much as research design focuses on respondent sampling as a component of valid inference to populations."3

Palmtop computers are increasingly used to manage the prompting as well as the data collection. A clear asset of the electronic diary is the possibility to accurately track compliance by date and time stamping of entries and by immediate storage of response time, response delay, as well as numbers and sources of missing records. ${ }^{50-55}$ Another asset concerns the assurance of acceptability and user-friendliness by flexible options to turn off the prompting and by modern interfaces ("point and touch") that allow to complete recordings quickly, naturally, and conveniently. ${ }^{3,55}$ The most important asset, however, is the enhancement of self-report reliability by the avoidance of recall bias, which hampers retrospective crosssectional measurement ${ }^{56,57}$ and paper diaries. ${ }^{3}$ With respect to pain assessment, electronic diaries were shown to be superior to paper diaries regarding true compliance, which in paper diaries was shown to be only a fraction of the reported adherence ${ }^{58}$; with regard to high compliance, patient satisfaction, ${ }^{5-61}$ and absence of reactivity: the electronic diary keeping did not affect the pain ratings. ${ }^{59}$ Research was also conducted to validate the electronic pain rating ${ }^{60,62}$ and established the nonequivalence between weekly pain recall and momentary pain reports averaged over the same week. ${ }^{63}$ Last, the type of data obtained with electronic real-time measurements also allows for a concise account of different sources of variance. A focus on between-patient differences - most prevalent in health psychological research and pursued in the present study - runs the risk of obtaining distorted results by directly analyzing these differences, because these can emerge in the absence of any significant within-patient association in the data. ${ }^{64}$ Studies on the issue of psychological states that typically fluctuate and wax and wane should not neglect but explicitly consider contextual or within-patient sources of variance. The present diary method is particularly suited to do so.

\section{Focus of the Present Paper}

Part I of the study focuses on pain report in CPD and its association with patient and spousal responses to pain. Because methods matter, we aim to corroborate and extend the existing evidence with momentary, real-time data, an effort to target psychologic functioning in CPD recently also undertaken by others. ${ }^{65,66}$ The aim to control for recall bias and account for within-patient variance of the present study seems mandatory to deepen the understanding of psychological functioning in chronic pain.

The research issues concern: 1) the extent to which fearavoidance, cognitive, and spousal pain responses statistically predict (that is, explain variance in) pain intensity in CPD; and 2 ) whether these predictions differ in patients with persistently chronic (>12 months), recently chronic (6-12 months), and prechronic (3-6 months) pain. Regarding issue 1, we expect to substantiate and extend the associations established thus far. 
This would strengthen the evidence of the impact of psychological functioning on CPD and confirm the multidimensionality of chronic pain. ${ }^{20}$ Issue 2 is regarded as primarily relevant concerning the association between psychologic functioning and CPD disability (see part II of the study) where associations are expected to strengthen with longer pain duration. The issue is included here because stronger associations with longer pain duration between psychological functioning and pain intensity would indicate that interactions between psychologic functioning and pain are important ingredients of CPD maintenance.

\section{MATERIALS AND METHODS}

\section{Patients}

The study included 80 patients (women: 71\%) aged 18 to 60 years (mean 40.6, SD 6.7 years) who suffered from various types of IASP-classified chronic pain (Table 1) and were homemaker $(20 \%)$, employed $(40 \%)$, or received a disability pension (40\%). Forty-four patients were recruited from a national Dutch CPD sample. ${ }^{67,68}$ Patients had to suffer for at least 6 months from unexplained pain or a symptomdiagnosed pain disorder. The pain had to be the most prominent aspect in the clinical presentation to the general practitioner, justify clinical attention, and have induced obvious discomfort for at least 1 month. To find enough participants with pain for less than 12 months, the remaining patients were recruited through physiotherapists $(\mathrm{N}=30)$ and a newspaper announcement $(\mathrm{N}=6)$. Recruitment continued until 2 matched and equal groups with pain $\leq 12$ and $>12$ months were formed. The group with pain $\leq 12$ months was then split into patients with pain for 3 to 6 months $(\mathrm{N}=15)$ and $>6$ to 12 months $(\mathrm{N}=25)$, which were again highly comparable.

\section{Electronic Momentary Assessment Measurements}

Data were collected with palmtop computers (PTCs) for 4 weeks, 4 times per day. The beeping signal was randomized within 2-hour time frames between, respectively, 8:00 to 11:00 AM, 11:30 AM to $2: 30 \mathrm{PM}, 3: 00$ to $6: 00 \mathrm{PM}$, and $6: 30$ to 9:30 PM. Unanswered signals were repeated after 5 minutes and, when not answered, were stored as missing. Patients were allowed to voluntarily skip 1 signal in succession per day in case of inconvenience. The total diary took about 5 minutes to complete. The items displayed ranged between 31 and 84, because the PTC was programmed to automatically skip items from the diary when certain conditions such as the actual presence of pain were not met at the moment of the signal.

Participants were visited at home for a briefing session, which included instruction, demonstration and practice with the PTC and ESM diary, explanation of the general procedure, and the signing of an informed consent form. About 2 days later and after 2 weeks of diary recording, they were contacted by phone for a second and a third briefing. During the 4 weeks of recording, assistance by phone was available in the case of problems. After completion patients were visited for a debriefing interview, receipt of a remuneration of Euro 45, and collection of the PTC.

\section{Construction and Content of the Electronic Diary}

A literature study on the subject of psychologic functioning in $\mathrm{CPD}^{4}$ identified the psychological pain responses presented in the introduction as well as 30 instruments in pain research. The subject matter of these instruments was reviewed to gear the first draft of an ESM diary list of items. It was not the purpose to literally adopt items, because ESM diary items must take the form of momentary self-statements (e.g., "Right now, I...") in spoken language and "daily life vocabulary" and be as short and simple as possible to mimic an internal dialogue. ${ }^{45}$ In addition, item numbers should be kept as limited as possible: usually singular items are employed to assess a subjective state ("right now I feel guilty" assesses momentary guilt with maximized face-validity ${ }^{45}$ ). Because brief formulations do not always cover responses at issue sufficiently, more than 1 item may be required in which case internal consistency can be established, but construct measurement is explicitly not intended in ESM.

Seven of the 30 instruments provided items that served as rough concepts for the ESM diary list of items. These included the Multidimensional Pain Inventory (MPI ${ }^{69,70}$; Dutch version $^{71-73}$ ), the Fear-Avoidance Beliefs Questionnaire $\left(\mathrm{FABQ}{ }^{15}\right.$ ) the Tampa Scale for Kinesophobia $\left(\mathrm{TSK}^{74}\right.$; Dutch version ${ }^{75}$ ), the Coping Strategies Questionnaire $\left(\mathrm{CSQ}^{76}\right.$; Dutch version $\left.{ }^{77}\right)$, the Pain Cognitions Questionnaire $\left(\mathrm{PCQ}^{28}\right)$, Pain Cognition List $\left(\mathrm{PCL}^{78}\right)$, and Inventory of Negative Thoughts in Response to Pain $\left(\right.$ INTRP $\left.^{27}\right)$. The fitting to ESM requirements pertained to formulations in terms of momentary self-statements and succinct tailoring of the content, which in most cases meant that more specificity was needed [for example, the FABQ contains items for fear of movement in case of pain ("physical exertion worsens my pain") and anticipated pain ("physical exertion can hurt me"), which were tailored to movement instead of physical exertion in the diary items for pain-related fear; this was in accordance with the TSK item on the same issue ("The safest way to prevent my pain to worsen is to simply avoid unnecessary movements"), which was too long and too complex to be adopted]. It also occured that the content of items was integrated for the purpose of a more general formulation [for example, 2 items for optimism derived from the PCQ ("tell yourself to be optimistic") and PCL ("In spite of the pain I am confident about the future") were integrated into 1 ESM item ("right now I continue to be optimistic in spite of the pain")].

The ESM item for pain intensity was quite close to that of the MPI (which is tailored to the present and rated on a 7-point scale) and appeared in every diary. Fear-avoidance responses to pain were also rated in each diary, but because fear as well as avoidance may be anticipatory, these items covered actual as well as expected pain with slightly different wordings. And because attention to bodily sensations may not always be a conscious process, the item for bodily vigilance was tailored to the consequence of increased awareness of bodily sensations, instead of asking for it directly. Cognitive and spousal responses to pain were assessed only when the 
TABLE 1. Medical Condition (Pain Duration and Severity [Mean ( \pm SD)] Pain Condition, Medication Use, Comorbid Conditions), Electronic Diary Assessments of Pain Intensity, Psychological Pain Responses, and Compliance [Mean ( \pm SD)]

\begin{tabular}{|c|c|c|c|}
\hline & $\begin{array}{c}\text { Group 1 } \\
\text { Pain 3-6 }(\mathrm{N}=15) \mathrm{mos} \\
\end{array}$ & $\begin{array}{c}\text { Group 2 } \\
\text { Pain 6-12 }(\mathrm{N}=25) \mathrm{mos} \\
\end{array}$ & $\begin{array}{c}\text { Group 3 } \\
\text { Pain }>12(N=40) \text { mos } \\
\end{array}$ \\
\hline $\begin{array}{l}\text { Pain duration* } \\
\text { (in months) }\end{array}$ & $4.3(0.8) \dagger$ & $8.9(2.5) \dagger$ & $125.6(88.9) \dagger$ \\
\hline \multicolumn{4}{|l|}{ Pain severity* } \\
\hline (MPI-DV) & $4.1(1.8)$ & $4.0(1.0)$ & $4.1(1.4)$ \\
\hline \multicolumn{4}{|l|}{ IASP classification $(\%) \ddagger$} \\
\hline Head/face/mouth & 6.7 & 0 & 10.5 \\
\hline Cervical & 40.0 & 37.5 & 23.7 \\
\hline Shoulder/upper limbs & 33.3 & 12.5 & 5.3 \\
\hline Thoracic & 0 & 0 & 0 \\
\hline Abdominal & 0 & 8.3 & 2.6 \\
\hline Lower back/spine & 13.3 & 25.0 & 21.1 \\
\hline Lower limbs & 0 & 8.3 & 5.3 \\
\hline Pelvic & 0 & 0 & 0 \\
\hline Anal/genital & 0 & 0 & 0 \\
\hline More than 3 major sites & 6.7 & 8.3 & 31.6 \\
\hline \multicolumn{4}{|l|}{ Medication use $(\mathrm{N}) \ddagger$} \\
\hline Nonopioid analgesics & 8 & 14 & 21 \\
\hline Opioids & 1 & 1 & 2 \\
\hline Antimigraine & 0 & 1 & 2 \\
\hline Antidepressants & 2 & 2 & 3 \\
\hline Sedatives & 2 & 4 & 5 \\
\hline Miscellaneous & 4 & 2 & 12 \\
\hline \multicolumn{4}{|l|}{ Comorbid conditions $(\mathrm{N}) \ddagger$} \\
\hline Hypertension & 1 & 1 & 7 \\
\hline Cardiac problems & 0 & 2 & 1 \\
\hline Asthma & 2 & 2 & 4 \\
\hline Chronic bronchitis & 0 & 0 & 2 \\
\hline Allergy & 2 & 3 & 2 \\
\hline Stomach/intestinal & 1 & 2 & 6 \\
\hline Diabetes & 0 & 2 & 1 \\
\hline Hyperthroidism & 0 & 2 & 0 \\
\hline Epileptic condition & 0 & 0 & 1 \\
\hline \multicolumn{4}{|l|}{ Electronic diary assessments Pain $(1-7) \S$} \\
\hline Intensity $(\mathrm{N}=7121)$ & $2.9(1.4)$ & $3.8(1.5)$ & $3.8(1.6)$ \\
\hline \multicolumn{4}{|l|}{ Psychological pain responses $(1-7) \S$} \\
\hline \multicolumn{4}{|l|}{ Fear-avoidance responses $(\mathrm{N}=7121)$} \\
\hline Pain-related fear & $2.9(1.0)$ & $3.4(1.5)$ & $3.2(1.4)$ \\
\hline Bodily vigilance & $3.3(1.6)$ & $3.8(1.7)$ & $3.5(1.8)$ \\
\hline Avoidance behavior & $4.0(1.4)$ & $4.2(1.5)$ & $4.2(1.2)$ \\
\hline \multicolumn{4}{|l|}{ Cognitive responses $(\mathrm{N}=5057)$} \\
\hline Catastrophizing & $3.0(1.1)$ & $3.3(1.1)$ & $3.4(1.0)$ \\
\hline Negative self-statements & $2.2(0.6)$ & $2.5(0.7)$ & $2.4(0.8)$ \\
\hline Optimism & $5.0(0.7)$ & $4.7(1.0)$ & $5.2(1.1)$ \\
\hline Control over the pain & $2.8(1.2)$ & $2.9(1.0)$ & $3.1(1.1)$ \\
\hline Spousal responses $(\mathrm{N}=1469)$ & $(\mathrm{N}=14)$ & $(\mathrm{N}=20)$ & $(\mathrm{N}=36)$ \\
\hline Reinforcement of pain behavior & $3.3(1.4)$ & $4.1(1.5)$ & $4.0(1.5)$ \\
\hline Reinforcement of well behavior & $3.1(1.6)$ & $2.9(1.9)$ & $3.0(1.5)$ \\
\hline Punishment of pain behavior & $4.2(1.8)$ & $4.4(1.4)$ & $4.4(1.9)$ \\
\hline Punishment of well behavior & $3.1(1.5)$ & $3.7(1.6)$ & $3.6(1.7)$ \\
\hline \multicolumn{4}{|l|}{ Compliance $\S$} \\
\hline Completed diaries in $4 \mathrm{wks}$ & $86(18)$ & $86(16)$ & $93(13)$ \\
\hline
\end{tabular}

*According to $\chi^{2}$ testing.

$\dagger$ Between-group difference: $P<0.001$

$¥$ The expected numbers per cell were too small to allow for $\chi^{2}$ testing of between-group differences in pain location, medication use, and comorbid conditions

$\S$ Tested with ANOVA for 3 groups and post-hoc t-tests; between-group differences not significant. 
TABLE 2. ESM Items for Pain Intensity and Psychological Pain Responses in the Electronic Diary

\begin{tabular}{|c|c|c|c|c|c|}
\hline Variables & Geared by & $C-\alpha$ & Item(s) & Rating & Occurence \\
\hline Pain intensity & MPI & & How much pain do I feel right now? & $\begin{array}{l}\text { 7-point } \\
\text { scale* }\end{array}$ & In all diaries \\
\hline \multicolumn{6}{|l|}{ Psychological responses } \\
\hline Fear-avoidance responses & & & Right now... & \multirow{5}{*}{$\begin{array}{l}\text { 7-point } \\
\text { scale } \dagger\end{array}$} & \\
\hline \multirow[t]{2}{*}{ Pain related fear } & FABQ; TSK & 0.79 & $\begin{array}{l}\text { I am afraid to move because of the pain } \\
\text { (with pain) } \\
\text { I am afraid to move, because this may } \\
\text { provoke my pain (with no pain) } \\
\text { The pain will become worse if I move just a } \\
\text { little bit (with pain) }\end{array}$ & & \multirow{4}{*}{ In all diaries } \\
\hline & & & $\begin{array}{l}\text { The pain will reoccur if I move just a } \\
\text { little bit (with pain) }\end{array}$ & & \\
\hline Bodily vigilance & - & - & I feel everything that is happening in my body & & \\
\hline Avoidance behavior & - & - & $\begin{array}{l}\text { I avoid physical exertion that may worsen my } \\
\text { pain (with pain) } \\
\text { I avoid physical exertion that } \\
\text { may trigger my pain (with no pain) }\end{array}$ & & \\
\hline Cognitive responses & & & Right now... & \multirow{5}{*}{$\begin{array}{l}\text { 7-point } \\
\text { scale } \dagger\end{array}$} & \multirow{5}{*}{$\begin{array}{l}\text { When pain was } \\
\text { experienced }\end{array}$} \\
\hline Catastrophizing & CSQ & 0.61 & $\begin{array}{l}\text { I believe that I will never get rid of my pain } \\
\text { I think it is terrible to have such pain } \\
\text { the pain is too much for me }\end{array}$ & & \\
\hline Negative self-statements & PCQ; INTPR & 0.43 & $\begin{array}{l}\text { I blame myself for having pain } \\
\text { I burden others with my pain } \\
\text { I feel useful }\end{array}$ & & \\
\hline Optimism & PCQ; PCL & - & I continue to be optimistic in spite of the pain & & \\
\hline Control over the pain & MPI & - & There is nothing/can do to ease my pain & & \\
\hline Spousal responses & & & $\begin{array}{l}\text { How does he/she respond to my pain? Right } \\
\text { now he/she... }\end{array}$ & \multirow{5}{*}{$\begin{array}{l}\text { 7-point } \\
\text { scale } \dagger\end{array}$} & \multirow{5}{*}{$\begin{array}{l}\text { When pain was } \\
\text { experienced and } \\
\text { the spouse was } \\
\text { present }\end{array}$} \\
\hline Reinforcement of pain behavior & MPI & 0.96 & $\begin{array}{l}\text { Is particularly kind spares me } \\
\text { Takes over duties }\end{array}$ & & \\
\hline Punishment of pain behavior & MPI & 0.55 & Ignores my pain is annoyed with me & & \\
\hline Reinforcement of well behavior & - & 0.89 & $\begin{array}{l}\text { Encourages me to go on } \\
\text { Encourages me to be active }\end{array}$ & & \\
\hline Punishment of well behavior & - & 0.93 & $\begin{array}{l}\text { Indicates that I should take rest } \\
\text { notes that I demand too much of my body }\end{array}$ & & \\
\hline
\end{tabular}

*Anchored 1 (none), 4 (moderate), 7 (severe).

†Anchored 1 (not at all), 4 (moderately), 7 (very much).

patient was in actual pain. Assessment of the spousal responses required in addition that the spouse be with the patient at the moment of recording, which was ascertained by preparatory questions. Only when the patient had indicated that the spouse was present and, in addition, that the spouse actually knew that the patient at present suffered from pain, the question "how does he/she respond to my pain?" occurred to introduce the spousal items.

The instruments did not cover all issues pertaining to the present study. Items for which no clue emerged were constructed and subjected to a procedure of interjudge accordance. Polarity of some of the items was then reverted to balance positive and negative formulations to avoid response sets. ${ }^{4}$ A pilot study in 4 patients with chronic pain established the feasibility and patient acceptability of the electronic diary and demonstrated the usefulness of the ESM items. ${ }^{4}$

Table 2 presents the ESM diary items with sources where appropriate. More relevant to efforts to reproduce the present study are the literal wordings of the items employed, which are therefore provided. Cronbach alpha coefficients of variables represented by several diary items show that internal consistency was moderate for "negative self-statements" $(0.43)$ and sufficient to high in the remaining variables $(0.55$ to 0.96$)$.

\section{Characteristics of the Method, Sampling Process, and Diary Data}

The following important prerequisites were established, which distinguish electronic from paper diary methods of pain monitoring. First, compliance with the diary keeping was high (Table 1) and the pain ratings were stable across the 4-week period, indicating the absence of instrument reactivity, ${ }^{68}$ which is a common flaw of paper diaries of pain. ${ }^{79-81}$ Second, concordance with cross-sectional instruments usually found with paper diaries ${ }^{70,73,82}$ was moderate, ${ }^{68}$ which attests that the present electronic method indeed is not equivalent to 
cross-sectional measurement and paper diaries. ${ }^{3}$ Interestingly, the present diary systematically yielded significantly lower outcomes on pain intensity than the cross-sectional pain assessment, even when both methods covered the same week, ${ }^{68}$ which confirms that pain recall is often an overestimation ${ }^{3,83}$ and supports the utility of the present method.

The sampling process was not hampered by unusual events: according to the debriefing interview, all patients regarded the 4 weeks of recording as representative of their normal life. Most patients carried the PTC for exactly 4 weeks $(\mathrm{N}=74) ; 3$ patients carried it for 3 to 4 weeks, 2 for a longer period and the recording of 1 patient was stopped after 14 days because of exceptional technical problems. Of the signals (mean: 108.4, range 40-140), 10.6\% were not responded to, $1.5 \%$ were voluntarily skipped (also indicative of high compliance because participants were allowed to skip 1 signal per day), and $5.1 \%$ were missed due to technical problems, which incidentally accounted for the missing of successive diary entries. Nonresponse was not related to time of day. This left us with 7121 valid diaries (mean 89.3; range 30-115). Because the entrance of cognitive responses depended on actual pain (5057 diaries) and those of spousal responses depended in addition on the presence of the spouse (1469 diaries), a data set of 1469 diaries contained all of the psychological variables.

\section{Data Analysis}

The beep-diary observations are nested within days, which are nested within patients. This implies that 2 withinpatient levels (beep level and day level) and 1 between-patient level (patient level) of variance are to be distinguished. To adequately account for the hierarchical nesting, a multilevel regression approach ${ }^{84,85}$ was used. This method treats data at the level of the single observation, does not require balanced data sets, and provides high power for the significance testing while keeping all the original information. ${ }^{86}$ Multilevel analysis is recommended for ESM data ${ }^{87}$ and has recently spread out over research in medicine and the social sciences. ${ }^{88-90}$

The intercept and slope parameters of multilevel analysis are similar to the unstandardized coefficients in a multiple regression analysis. Multilevel modeling fits a curve for the dependent variable (here: pain) for each patient. This is necessary given the dependency of the within-patient measures: the beep-level measurements within a patient tend to be more alike than beep-level measurements chosen at random. The curves are characterized by their intercept (or level) and slope (rate of change). In models that follow, independent variables explain between-patient variation in level and slope of the pain curves.

We underscore that the term "predictor" is used in the statistical sense: it refers to the power of a given variable to significantly explain variance in pain intensity. The analysis consisted of fitting a fixed sequence of models for the separate testing of the 3 sets of psychologic responses as potential predictors of pain intensity; the sequence was then repeated to simultaneously test pain predictors that were significant in the separate analyses. Nonsignificant variables were removed from the testing of subsequent models. In addition, the complete cycle of model testing was repeated to establish time-lagged associations between the psychological variables and pain intensity on time $\mathrm{N}+1$. The outcomes did not add to the results presented and thus were omitted from the paper. Model 1, the intercept-only or empty model, served to decompose the total random variance in pain intensity according to the contribution of the levels into 3 proportions. Model 2 controlled for timedependent trends in pain intensity: time, time $^{2}$ and time ${ }^{3}$ were entered successively to determine the effects of time-of-day on pain. Then psychological variables were entered in model 3 to determine the percentage of explained variance relative to the proportions of random variance per level as obtained in model 2 . In model 4, pain duration was entered to test for betweengroup differences in pain prediction. Multilevel modeling was performed using the program $\mathrm{MLwiN},{ }^{91}$ and the significance of the variances was determined by the likelihood ratio test. ${ }^{92}$ Beta values were standardized for presentation in Table 3, where only significant results are presented for the sake of clarity.

\section{RESULTS}

\section{Characteristics of the Diary Variables}

The descriptive characteristics of the ratings, summarized in Table 1, were computed after data aggregation per patient with polarity of items reverted where appropriate to account for the within-patient dependency in the data. Compliance with the diary rating was high and almost equal in the 3 groups. No significant between-group differences were found, although patients with prechronic pain tended to report lower scores on pain intensity and on spousal reinforcement of pain and punishment of well behavior. Table 4 provides the Pearson product-moment (PM) correlations between the psychologic variables.

The associations presented in Table 4 are stable and representative, given the strong correspondence with correlations computed for the larger data sets of 5057 and 7121 observations (not presented). Spousal responses were quite independent from the patients' own responses to their pain. Three of the spousal responses shared $38 \%$ to $50 \%$ in variance $(r=0.62$ to 0.71$)$. Of the patients' own pain responses, fear-avoidance shared $2 \%$ to $21 \%(r=0.15$ to 0.46$)$ and cognitive responses $0 \%$ to $23 \%(r=0.02$ to -0.48$)$ in variance.

\section{Prediction of Pain Intensity by Psychological Variables}

Before entering predictors in the multilevel regression analyses, multicollinearity was checked by standard linear regression analysis (all variable inflation factors [VIFs] were $<3$ ). Table 3 shows the results of the separate and simultaneous testing of the psychologic pain responses in predicting pain intensity. The results include: significant predictors with beta coefficients indicating their predictive power; distributions of the random variance over the 3 levels; percentages of explained variance $\left(R^{2}\right)$ per level; and significance of the explained variance (model fit). The testing of differences in the associations according to pain duration was not significant in all of the analyses. The model 4 testing was therefore omitted. 
TABLE 3. Variance in Pain Intensity Explained Separately and Simultaneously by Fear-Avoidance, Cognitive, and Spousal Pain Responses

\begin{tabular}{|c|c|c|c|c|c|c|c|c|}
\hline \multirow{2}{*}{$\begin{array}{c}\text { Fear-Avoidance Responses } \\
\text { (Based on } 7121 \text { Diaries) }\end{array}$} & \multicolumn{2}{|c|}{ Model 1 (Intercept-Only) } & \multicolumn{3}{|c|}{ Model 2} & \multicolumn{3}{|c|}{ Model 3} \\
\hline & Estimate & SE & Estimate & SE & Beta* & Estimate & SE & Beta* \\
\hline Intercept & 3.636 & $(0.171)$ & 2.357 & $(0.276)$ & & 0.186 & $(0.250)$ & \\
\hline Time & & & 0.001 & $(0.000)$ & $0.255 \dagger$ & 0.001 & $(0.000)$ & $0.216 \dagger$ \\
\hline Timeł & & & -0.000 & $(0.000)$ & $-0.158 \dagger$ & -0.000 & $(0.000)$ & $-0.149 \dagger$ \\
\hline Pain-related fear & & & & & & 0.209 & $(0.008)$ & $0.342 \dagger$ \\
\hline Bodily vigilance & & & & & & 0.202 & $(0.015)$ & $0.195 \dagger$ \\
\hline \multirow[t]{2}{*}{ Avoidance behavior } & & & & & & 0.093 & $(0.010)$ & $0.087 \dagger$ \\
\hline & Random $\neq$ & & Random $\ddagger$ & & & Random $\ddagger$ & \multicolumn{2}{|c|}{ Explained $\left(\mathbf{R}^{2}\right) \S$} \\
\hline \multicolumn{9}{|l|}{ Variance } \\
\hline Patient level & 2.313 & & 2.317 & $(56 \%)$ & & 1.486 & \multicolumn{2}{|c|}{$36 \%$} \\
\hline Day level & 0.450 & & 0.470 & $(12 \%)$ & & 0.309 & \multicolumn{2}{|c|}{$34 \%$} \\
\hline Deep level & 1.368 & & 1.312 & $(32 \%)$ & & 1.122 & \multicolumn{2}{|c|}{$14 \%$} \\
\hline Model fit & 24365.3 & & 24161.5 & & & 22754.5 & \multicolumn{2}{|c|}{$(P=0.000)$} \\
\hline \multirow{2}{*}{$\begin{array}{l}\text { Cognitive Responses } \\
\text { (Based on } 5057 \text { Diaries) }\end{array}$} & \multicolumn{2}{|c|}{ Model 1 (Intercept-Only) } & \multicolumn{3}{|c|}{ Model 2} & \multicolumn{3}{|c|}{ Model 3} \\
\hline & Estimate & SE & Estimate & SE & Beta* & Estimate & SE & Beta* \\
\hline Intercept & 4.640 & $(0.106)$ & 3.484 & $(0.197)$ & & 2.065 & $(0.192)$ & \\
\hline Time & & & 0.001 & $(0.000)$ & $0.360 \dagger$ & 0.001 & $(0.000)$ & $0.259 \dagger$ \\
\hline Timer $\ddagger$ & & & -0.000 & $(0.000)$ & $-0.232 \dagger$ & -0.000 & $(0.000)$ & $-0.179 \dagger$ \\
\hline Catastrophizing & & & & & & 0.156 & $(0.005)$ & $0.478 \dagger$ \\
\hline Negative self-statements & & & & & & 0.043 & $(0.006)$ & $0.095 \dagger$ \\
\hline \multirow[t]{2}{*}{ Optimism } & & & & & & 0.032 & $(0.011)$ & $0.035 \dagger$ \\
\hline & Random $\neq$ & & Random $\ddagger$ & & & Random $\ddagger$ & \multicolumn{2}{|c|}{ Explained $\left(\mathbf{R}^{2}\right) \S$} \\
\hline \multicolumn{9}{|l|}{ Variance } \\
\hline Patient level & 0.871 & & 0.884 & $(54 \%)$ & & 0.632 & \multicolumn{2}{|c|}{$29 \%$} \\
\hline Day level & 0.203 & & 0.219 & $(14 \%)$ & & 0.126 & \multicolumn{2}{|c|}{$42 \%$} \\
\hline Beep level & 0.562 & & 0.521 & $(32 \%)$ & & 0.413 & & \\
\hline Model fit ${ }^{\|}$ & 12971.6 & & 12724.9 & & & 11278.5 & & 000) \\
\hline & Model 1 (Int & t-Only) & & Model 2 & & & Model 3 & \\
\hline (Based on 1469 Diaries) & Estimate & $\overline{S E}$ & Estimate & SE & Beta* & Estimate & SE & Beta* \\
\hline Intercept & 4.602 & $(0.123)$ & 4.174 & $(0.155)$ & & 3.868 & $(0.156)$ & \\
\hline Time & & & 0.000 & $(0.000)$ & $0.085 \dagger$ & 0.000 & $(0.000)$ & $0.057 \dagger$ \\
\hline Reinforcement of pain behavior & & & & & & 0.030 & $(0.006)$ & $0.186 \dagger$ \\
\hline Reinforcement of well behavior & & & & & & -0.059 & $(0.012)$ & $-0.161 \dagger$ \\
\hline Punishment of well behavior & & & & & & 0.044 & $(0.012)$ & $0.141 \dagger$ \\
\hline & Random $\neq$ & & Random $\ddagger$ & & & Random $\ddagger$ & Expla & $\left(R^{2}\right) \S$ \\
\hline Variance & & & & & & & & \\
\hline Patient level & 0.960 & & 0.967 & $(56 \%)$ & & 0.863 & & \\
\hline Day level & 0.231 & & 0.233 & $(14 \%)$ & & 0.192 & & \\
\hline Beep level & 0.513 & & 0.502 & $(30 \%)$ & & 0.499 & & \\
\hline Model fit & 3869.4 & & 3845.6 & & & 3739.4 & & 000) \\
\hline & & & & & & & Model 3 & \\
\hline (Based on 1469 Diaries) & Mod & & & Model 29 & & Estimate & SE & Beta* \\
\hline Intercept & & & & & & 1.654 & $(0.164)$ & \\
\hline Time & & & & & & 0.000 & $(0.000)$ & $0.023 \dagger$ \\
\hline Catastrophizing & & & & & & 0.124 & $(0.008)$ & $0.369 \dagger$ \\
\hline Pain-related fear & & & & & & 0.087 & $(0.011)$ & $0.211 \dagger$ \\
\hline Bodily vigilance & & & & & & 0.096 & $(0.022)$ & $0.137 \dagger$ \\
\hline Reinforcement of pain behavior & & & & & & 0.012 & $(0.005)$ & 0.074 \\
\hline
\end{tabular}


TABLE 3. (continued) Variance in Pain Intensity Explained Separately and Simultaneously by Fear-Avoidance, Cognitive, and Spousal Pain Responses

\begin{tabular}{|c|c|c|c|c|}
\hline \multirow{2}{*}{$\begin{array}{c}\text { Fear-Avoidance Responses } \\
\text { (Based on } 7121 \text { Diaries) }\end{array}$} & \multirow[b]{2}{*}{ Model 19} & \multicolumn{3}{|c|}{ Model 3} \\
\hline & & Estimate & SE & Beta* \\
\hline Punishment of well behavior & & 0.022 & $(0.010)$ & $0.070 \dagger$ \\
\hline Reinforcement of well behavior & & -0.024 & $(0.010)$ & $-0.066 \dagger$ \\
\hline Negative self-statements & & 0.030 & $(0.010)$ & $0.061 \dagger$ \\
\hline \multirow[t]{2}{*}{ Avoidance behavior } & & 0.027 & $(0.014)$ & $0.035 \dagger$ \\
\hline & & Random $\ddagger$ & \multicolumn{2}{|c|}{ Explained $\left(\mathbf{R}^{2}\right) \S$} \\
\hline \multicolumn{5}{|l|}{ Variance } \\
\hline Patient level & & 0.556 & \multicolumn{2}{|c|}{$42 \%$} \\
\hline Day level & & 0.103 & \multicolumn{2}{|c|}{$58 \%$} \\
\hline Beep level & & 0.368 & \multicolumn{2}{|c|}{$27 \%$} \\
\hline Model fit ${ }^{\|}$ & & 3224.1 & \multicolumn{2}{|c|}{$(P=0.000)$} \\
\hline \multicolumn{5}{|c|}{$\begin{array}{l}* \text { Beta coefficients are standardized [SE (independent variable) } \times \text { estimate (dependence variable)/SE (dependent variable)]. } \\
\dagger \mathrm{P}<0.05 \text { [estimate (dependent variable) }>2 \times \mathrm{SE} \text { (dependent variable)]. } \\
¥ \text { The proportions are calculated relative to the total random variance. } \\
\S \text { Per level, the difference in explained variance as compared to the previous model is calculated as proportion of the random variance attributed to that level. } \\
\text { "Significance of the model with respect to the previous model. } \\
\text { TSee outcomes of the previous analysis based on the same number of diary observations. }\end{array}$} \\
\hline
\end{tabular}

Table 3 shows that substantial random variance $(56 \%)$ occurred at the patient-level; this is important because the study primarily aimed to explain between-patient differences. The remaining random variance was induced by within-patient differences between beeps (30\%) and between days (14\%). The model 2 testing revealed that pain intensity increased with time of day and - according to most analyses - leveled off at the end of day. Psychologic pain responses had, however, a stronger impact on pain intensity than had time of day. Table 3 provides strong evidence that psychologic pain responses explained pain intensity. Of these, the patients' psychologic responses were stronger pain predictors than were the spousal responses. The simultaneous testing showed that catastrophizing (beta: $0.37)$, pain-related fear $(0.21)$, and bodily vigilance $(0.14)$ were the strongest predictors of pain intensity. As expected, however, spousal reinforcement of pain behavior (0.07) and punishment of well behavior $(0.07)$ were positively related to pain intensity, whereas reinforcement of well behavior $(-0.07)$ was negatively related to pain intensity.

So far the percentages of explained variance were calculated within levels. What counts in the end, however, are the explained proportions of the total random variance in pain intensity. Table 5 summarizes these calculations and shows that psychological variables explained almost $40 \%$ of the total variance in pain intensity: $23.5 \%$ were due to differences between patients, $8.1 \%$ to differences in time of day, and another $8.1 \%$ to differences between days.

\section{DISCUSSION}

In this study, a truly prospective, accurate, and highdensity diary method ( $>82 \%$ valid entries; $>7100$ diaries $)$ and meticulous control over within-patient variance detected between-patient differences in chronic pain not detected by cross-sectional questionnaires. ${ }^{68}$ Psychological pain responses

TABLE 4. Pearson PM Correlation Between Psychological Pain Responses Assessed With the Electronic Diary $(\mathrm{N}=1469)$

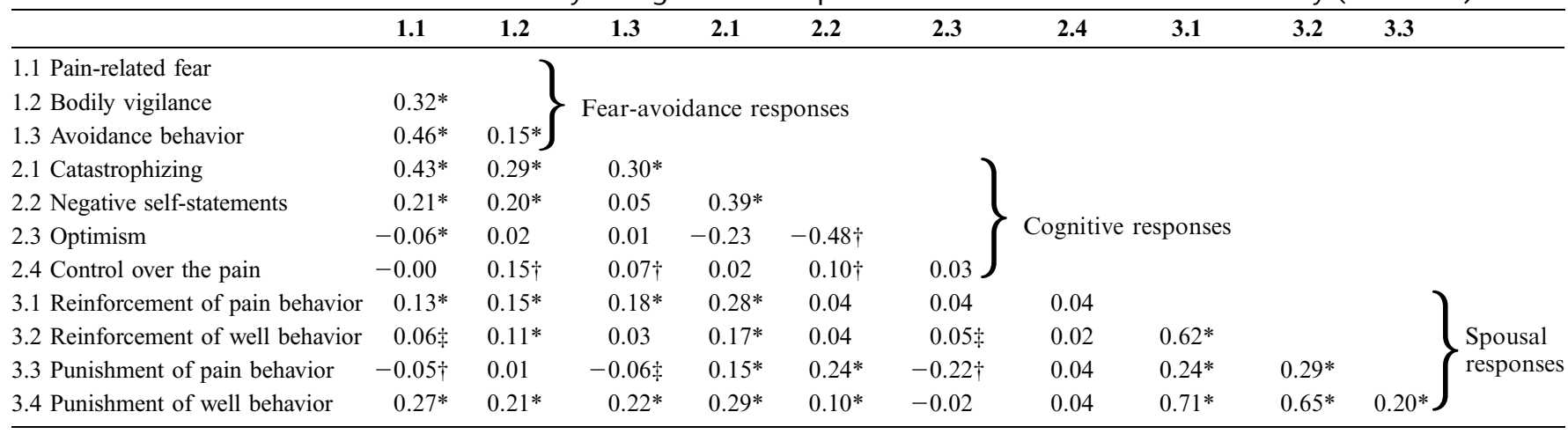

$* P<0.001 \mathrm{tt} ; \uparrow P<0.01 \mathrm{tt} ; \ddagger P<0.05 \mathrm{tt}$. 
TABLE 5. Proportion of the Total Variance in Pain Intensity Explained Separately and Simultaneously by Fear-Avoidance, Cognitive and Spousal Pain Responses.

\begin{tabular}{|c|c|c|c|c|}
\hline Predictor Variables & Patient Level & Day Level & Beep Level & $\begin{array}{c}\text { Total } \\
\text { (All Levels) }\end{array}$ \\
\hline Fear-avoidance responses $(\mathrm{N}=7121)$ & $(36 \times 0.56) 20.2 \%$ & $(34 \times 0.12) 4.1 \%$ & $(14 \times 0.32) 4.5 \%$ & $27.8 \%$ \\
\hline Cognitive responses $(\mathrm{N}=5057)$ & $(29 \times 0.54) 15.7 \%$ & $(42 \times 0.14) 5.9 \%$ & $(21 \times 0.32) 6.7 \%$ & $28.3 \%$ \\
\hline Spousal response $(\mathrm{N}=1469)$ & $(11 \times 0.56) 6.2 \%$ & $(18 \times 0.14) 2.5 \%$ & $(2 \times 0.30) 0.6 \%$ & $9.3 \%$ \\
\hline $\begin{array}{l}\text { Fear-avoidance, cognitive and spousal } \\
\text { pain responses }(\mathrm{N}=1469)\end{array}$ & $(42 \times 0.56) 23.5 \%$ & $(58 \times 0.14) 8.1 \%$ & $(27 \times 0.30) 8.1 \%$ & $39.7 \%$ \\
\hline
\end{tabular}

explained $40 \%$ of the total variance in pain intensity: almost $24 \%$ due to differences between and $16 \%$ due to momentary differences within the patients with CPD.

The finding that pain intensity differed to an almost equal extent between $(56 \%)$ as it did within patients $(44 \%)$ points out that momentary states of the patients with chronic pain, in particular the variation occurring across the day and to a lesser extent that occurring between days, are important. Pain intensity increased during the day and equalized at the end of the day, which is in accordance with previous findings. ${ }^{93-95}$ The results emphasize that research and clinical practice should accurately account for time of day in the assessment of pain. This requires prospective daily measurements, given the biased overestimation in retrospective pain assessments. ${ }^{3,68,83,96,97}$

In this study, psychological pain responses explained almost $24 \%$ of the total variance in pain intensity due to differences between the patients. This relatively large percentage adds to the evidence of the role of psychological factors in chronic pain obtained from cross-sectional and paper diaries. According to the separate testing of the 3 sets of pain predictors, the patients' fear-avoidance and cognitive responses were strong predictors explaining, respectively, $20 \%$ and $16 \%$ of the differences between patients, whereas spousal responses explained $6 \%$. The results substantiate results from previous research regarding the associations between pain report and, respectively, catastrophizing, ${ }^{21-25,66}$ pain-related fear, ${ }^{7,8}$ and attention to pain ${ }^{11,13,25}$ established mainly for musculoskeletal back pain and extend these to other IASP-classified types of chronic pain. Our study also supports the association between pain-related fear and bodily vigilance ${ }^{10,12,25}$ and confirmed the association between pain and spousal reinforcement of pain behavior. ${ }^{36-43}$ The results did not differ, however, between patients with prechronic, recently chronic, and persistently chronic pain. Thus, the study yielded no evidence so far that psychological pain responses are increasingly important with CPD development.

We also tested for a major somatic between-group difference, which was expected to influence pain intensity and its prediction, that is, the fact that $32 \%$ of the patients with persistently chronic pain suffered from pain in more than 3 major sites of the body compared to $7.5 \%$ of those with pain of more recent onset (Table 1). Multiple pain location was not significantly associated with pain intensity, however, and had no impact on pain prediction. Thus, psychological pain responses emerged as being more relevant to CPD pain intensity than multiple pain location. Of the singular psychological responses, catastrophizing emerged as the strongest predictor, followed by pain-related fear and bodily vigilance, whereas avoidance behavior was the weakest predictor. Spousal pain responses were relatively weak predictors as well. As expected, however, reinforcement of pain and punishment of well behavior predicted the patients' pain intensity positively, whereas reinforcement of well behavior predicted it negatively.

It is understandable that spousal responses emerged as weaker predictors of the patients pain than did the patients' own pain responses. We must consider that the association between the patients' pain and spousal pain responses is more complex and difficult to measure than that between the patients' pain and own pain responses. First, a second person is involved. Second, spousal impact is expected to act primarily on pain behavior, which constitutes a different dimension of chronic pain. Research on spousal pain responses was inconclusive concerning best measurement. ${ }^{36,37,41,98}$ We used a patient measure of spousal responses, which was advocated ${ }^{41}$ and makes sense considering that the patients' interpretation could mediate the influence of the spouses' response on his/her pain behavior. ${ }^{17}$ On the other hand, the patients' assessment of spousal responses can be inflated by social desirability or wishful thinking. This was taken as an argument in favor of observational measures, ${ }^{98}$ which did not solve the issue, however, because spousal responses where not significant when pain behavior was observed directly. ${ }^{99}$ It is unclear what type of cognitive processing is actually at stake in behavior conditioning, and we have no way to secure that the patients' electronic assessment of spousal responses was free of social desirability or wishful thinking, which may have hampered the present results. Furthermore, if spousal responses were to have an influence, it is likely that this influence affects rest taking or immobility (which is pain behavior reflecting CPD disability) more strongly than pain intensity per se. Part II of the present study will show whether this is indeed the case. Given all of these considerations, it is thus quite remarkable that spousal responses predicted any of the patients pain intensity in the present study. This may be due to the scrutiny of the electronic method employed, which ascertained true contextual measurement of spousal pain responses confined to $21 \%$ of the data. Our own findings point out that conscientious account of the context is mandatory. Our finding that solicitous spousal pain responses were significantly increased in the 40 patients with persistently chronic pain was based on all of the 7121 diaries. $^{68}$ This was not confirmed when the analysis was confined to the 1469 diaries where the spouse was actually present and responded to actual pain in the patient. The present study thus supports the relevance of spousal influences in 
CPD, notwithstanding the unresolved issue of best methodology, and underscores that the context dependency of this type of variables must be accounted for in future research.

The present study also emphasizes that cognitiveaffective and behavioral variables should in general be carefully distinguished in pain research. Most of the variables in the present study — including pain intensity - represent an internal sensation, experience, or reflection. Therefore, our finding that pain intensity was more strongly related to catastrophizing, pain-related fear, and bodily vigilance than to avoidance (a behavioral measure) might not come as a surprise. One would expect avoidance behavior to be related to behavioral immobility due to pain, which is among the topics of part II of this study.

The overruling importance of catastrophizing in the prediction of pain intensity is impressive in our data. Catastrophizing was, however, also associated with most of the other psychological pain responses. This suggests that catastrophizing may - fueled by fear and bodily vigilancedrive the downward spiral of behavioral avoidance, immobility, deconditioning, and pain maintenance in CPD. ${ }^{6,25}$ The finding that prediction differences between patients with prechronic, recently chronic, and persistently chronic pain were not significant may indicate that psychological pain responses and their association with pain intensity occur early and acquire stability right from the onset of chronic pain development. This would mean that maladaptive catastrophizing, fear, and vigilance impact on pain intensity right from the start of the pain problem. The design of the present study does not allow for such an inference, however. As stated, addressing this issue adequately requires longitudinal research within the same patients over time.

The present study is also of clinical relevance to the issue of persistent pain. Due to inherent subjectivity, pain is difficult to quantify or prove, while adequate assessment requires judgment of the magnitude of the problem concerning the extent to which the patient is suffering and disabled. ${ }^{100}$ Both the method and the results of the present study may serve this aim. Concerning the method, the rational for a pain diary is sound, but an electronic diary is definitely superior to paper formats regarding patient compliance, patient acceptability, absence of instrument reactivity, and assessment sensitivity, accuracy, and reliability. ${ }^{3}$ In addition to assessment, electronic diaries will also open new and solid windows to the monitoring and evaluation of treatment effects in chronic pain. ${ }^{63}$ Although innovations are fast and financial commitments drop, it is certain that purely technical solutions will never suffice without adequate clinical expertise. This is even truer when electronic devices are made interactive for clinical purposes, which is a step we are presently undertaking. ${ }^{55,68}$ Therefore, results as obtained with the present study are valuable to gear electronic assessment and treatment monitoring in the hands of experienced pain clinicians. Concerning the content of the present results, catastrophizing, pain-related fear, and bodily vigilance were emphasized to mark the dimension of suffering in chronic pain. ${ }^{20}$ Suffering is a nebulous concept ${ }^{101}$ it is difficult to identify, ${ }^{100}$ and its relation to persistent pain is unclear for most physicians. ${ }^{101}$ Nonetheless, to catch and tackle it proactively is an urgent matter in pain management, particularly in older adults, comparable to the age group studied here. ${ }^{102}$ The present results may increase awareness of the nature of suffering in chronic pain in physicians and the general public, may urge physicians to immediately counteract maladaptive catastrophizing, fear, and vigilance in pain patients, and may steer pain treatment to the amelioration of unnecessary suffering and the prevention of maladaptive avoidance, immobility, and deconditioning. For this purpose, it is promising that research in CPD recently started to tailor interventions to the markers of suffering identified in the present study. ${ }^{103-105}$

In conclusion, the present study showed: 1) that psychological responses to pain explained almost $24 \%$ of CPD patient intrinsic variance in pain intensity. The strongest pain predictors were catastrophizing, pain-related fear, and bodily vigilance, but spousal responses to the patients' pain and well behavior predicted pain too, but to a lesser extent. These results reflect associations, not causal relations, between psychological functioning and pain. 2) This study demonstrated unmistakably that variance in CPD pain intensity depends on differences between patients but to a substantial extent also on momentary states. This is relevant because psychological pain responses explained another $16 \%$ of the pain variance on the level of within-patient differences. We thus conclude that momentary states must be acknowledged in the assessment of chronic pain, must be systematically and explicitly accounted for in research, and are relevant to the monitoring and evaluation of treatment gains. 3) Due to the scrutiny of the diary method, patient selection, and data analysis, the results firmly consolidate the role of psychological functioning in a broad range of IASP-classified types of chronic pain but prove that psychologic functioning influences pain severity causally is yet to be established. Part II of the study applies the same scrutiny in quest of the associations between psychological pain responses and disability in CPD.

\section{ACKNOWLEDGMENTS}

The authors thank Peter C. Honkoop for adapting the PTC software to the requirements of this study and Lisalotte C. B. Verspui for assisting in the acquisition of the data.

\section{REFERENCES}

1. IASP. Classification of chronic pain. Description of pain syndromes and definitions of pain terms. Pain. 1986;(suppl):S3.

2. Turk DC, Okifugi A. Psychological factors in chronic pain: evolution and revolution. J Consult Clin Psychol. 2002;70:678-690.

3. Gendreau M, Hufford MR, Stone AA. Measuring clinical pain in chronic widespread pain: selected methodological issues. Best Pract Res Clin Rheum. 2003;17:575-592.

4. Peters ML, Sorbi MJ. Determinants and consequences of the chronic benign pain disorder. Part I: empirical studies; Part II: development of diary items; Part III: feasibility pilot. Reports of NWO Chronic Disease Program grant \# 940-31-033; Utrecht University; 1997.

5. Lousberg HB. Chronic Pain. Multiaxial Assessment and Behavioral Mechanisms. Maastricht: Datawyse/Universitaire Pers Maastricht; 1994.

6. Vlaeyen JWS, Linton SJ. Fear-avoidance and its consequences in chronic musculoskeletal pain: a state of the art. Pain. 2000;85:317-332.

7. Hadjistavaropoulos HD, LaChapelle DL. Extent and nature of anxiety experiences during physical examination of chronic low back pain. Behav Res Ther. 2000;38:3-29. 
8. van den Hout JHC, Vlaeyen JWS, Houben RMA, et al. The effects of failure feedback and pain-related fear on pain report, pain tolerance and pain avoidance in chronic low back pain patients. Pain. 2001;92:247257.

9. Crombez G, Vlaeyen JW, Heuts PH, et al. Pain-related fear is more disabling than pain itself: evidence on the role of pain-related fear in chronic back pain disability. Pain. 1999;80:329-339.

10. Crombez G, Eccleston C, Baeyens F, et al. Attention to chronic pain is dependent upon pain-related fear. J Psychosom Res. 1999;47:403-410.

11. McCracken LM. 'Attention' to pain in persons with chronic pain: a behavioral approach. Behav Ther. 1997;28:271-284.

12. Peters ML, Vlaeyen JWS, van Drunen C. Do fibromyalgia patients display hypervigilance for innocuous somatosensory stimuli? Application of a body scanning reaction time paradigm. Pain. 2000;86:283292.

13. Peters ML, Vlaeyen JWS, Kunnen AMW. Is pain-related fear a predictor of somatosensory hypervigilance in chronic low back pain patients? Behav Res Ther. 2002;40:85-103.

14. Vlaeyen JWS, Kole Snijders AMJ, Rotteveel AM, et al. The role of fear of movement/(re)injury in pain disability. J Occup Rehabil. 1995;5:235252.

15. Waddell G, Newton M, Henderson I, et al. A Fear-Avoidance Beliefs Questionnaire (FABQ) and the role of fear-avoidance beliefs in chronic low back pain and ability. Pain. 1993;52:157-168.

16. Asmundson GJG, Norton PJ, Norton GR. Beyond pain: the role of fear and avoidance in chronicity. Clin Psychol Rev. 1999;19:97-119.

17. Sharp TJ. Chronic pain: a reformulation of the cognitive-behavioural model. Behav Res Ther. 2001;39:787-800.

18. Turk DC, Flor H. Chronic pain: a biobehavioral perspective. In: Gatchel RJ, Turk DC, eds. Psychosocial Factors in Pain: Critical Perspectives. New York, NY: Guilford Press; 1999:18-34.

19. Philips HC. Avoidance behavior and its role in sustaining chronic pain Behav Res Ther. 1987;25:273-279.

20. Loeser JD. A definition of pain. Univ Washington Med. 1980;7:3-4.

21. Sullivan MJ, Thorn B, Haythornthwaite JA, et al. Theoretical perspectives on the relation between catastrophizing and pain. Clin $J$ Pain. 2001;17:52-64.

22. Sullivan MJ, Stanish W, Waite H, et al. Catastrophizing, pain and disability in patients with soft-tissue injuries. Pain. 1998;77:253-260.

23. Burckhardt CS, Clark SR, O'Reilly CA, et al. Pain-coping strategies of women with fibromyalgia: relationship to pain, fatigue and quality of life. J Musculoskel Pain. 1997;5:5-21.

24. Geisser ME, Robinson ME, Pickren WE. Differences in cognitive coping strategies among pain-sensitive and pain-tolerant individuals on the coldpressor test. Behav Ther. 1992;23:31-41.

25. Severeijns R, Vlaeyen JWS, van den Hout MA, et al. Pain catastrophizing predicts pain intensity, disability and psychological distress independent of the level of physical impairment. Clin $J$ Pain. 2001; $17: 165-172$

26. Goubert L, Crombez G, van Damme S. The role of neuroticism, pain catastrophizing and pain-related fear in vigilance to pain: a structural equation approach. Pain. 2004;107:234-241.

27. Gil M, Williams DA, Keefe FJ, et al. The relationship of negative thoughts to pain and psychological disease. Behav Ther. 1990;21:349-362.

28. Boston K, Pearce SA, Richardson PH. The Pain Cognition Questionnaire. J Psychosom Res. 1990;34:103-109.

29. Jensen MP, Turner JA, Romano JM, et al. Coping with chronic pain-a critical review. Pain. 1991;47:249-283.

30. Toomey TC, Mann JD, Abashian S, et al. Relationship between perceived self-control and pain, pain description and functioning. Pain. 1991;45:129-133.

31. Fordyce WE. The acquisition of operant pain. In: Fordyce WE, ed. Behavioral Methods for Chronic Pain and Illness. St. Louis, MO: Mosby Company; 1976:41-73.

32. Turk DC. Biopsychosocial perspective on chronic pain. In: Gatchel RJ, Turk DC, eds. Psychological Approaches to Pain Management. New York, NY: Guilford Press; 1996:3-32.

33. Lousberg R, Groenman NH, Schmidt AJM, et al. Operant conditioning of the pain experience. Percept Mot Skills. 1996;83:883-900.

34. Linton SJ, Gotestam KG. Controlling pain reports through operant conditioning: a laboratory demonstration. Percept Mot Skills. 1985;60: 427-437.
35. Jolliffe CD, Nicholas MK. Verbally reinforcing pain reports: an experimental test of the operant model of chronic pain. Pain. 2004; 107:167-175.

36. Romano JM, Turner JA, Friedman LS, et al. Sequential analysis of chronic pain behaviors and spouse responses. J Consult Clin Psychol. 1992;60:777-782

37. Romano MJ, Turner JA, Friedman LS, et al. Chronic pain patient-spouse behavioral interactions predict patient disability. Pain. 1995;63:353360 .

38. Lousberg R, Schmidt AJM, Groenman NH. The relationship between spouse solicitousness and pain behavior: searching for more experimental evidence. Pain. 1992:51:75-79.

39. Turk DC, Kerns RD, Rosenberg R. Effects of marital interaction on chronic pain and disability: examining the downside of social support. Rehabil Psychol. 1992;37:259-274.

40. Block AR, Kremer EF, Gaylor M. Behavioral treatment of chronic pain: the spouse as a discriminative cue for pain behavior. Pain. 1980;9:243252.

41. Flor H, Turk DC, Rudy TE. Relationship of pain impact and significant other reinforcement of pain behaviors: the mediating role of gender, marital status and martial satisfaction. Pain. 1989;38:45-50.

42. Flor H, Kerns RD, Turk DC. The role of spouse reinforcement, perceived pain and activity levels of chronic pain patients. J Psychosom Res. $1987 ; 31: 251-259$

43. Flor H, Knost B, Birbaumer N. The role of operant conditioning in chronic pain: an experimental investigation. Pain. 2002;95:111-118

44. Geiger G, Todd DD, Clark HB, et al. The effects of feedback and contingent reinforcement on the exercise behavior of chronic pain patients. Pain. 1992;49:179-185.

45. Delespaul PAEG. Assessing Schizophrenia in Daily Life. Maastricht: Datawyse/Universitaire Pers Maastricht; 1995.

46. de Vries MW, Delespaul PAEG. Zelfobservatie en intensieve timesampling in de psychiatrie. (Self-observation and intensive time sampling in psychiatry). In: Hoogduin CAL, Schnabel P, Vandereyken W, et al, eds. Jaarboek Psychiatrie en Psychotherapie. Meppel: Van Loghum Slaterus; 1993:94-108.

47. de Vries MW. The Experience of Psychopathology. Cambridge: Cambridge University Press; 1992.

48. Stone AA, Shiffman SS. Ecological Momentary Assessment (EMA) in behavioural medicine. Ann Behav Med. 1994;16:199-202.

49. Affleck G, Zautra A, Tennen H, et al. Multilevel daily process designs for consulting and clinical psychology: a preface for the perplexed. J Consult Clin Psychol. 1999;67:746-754.

50. Affleck G, Urrows S, Tennen H, et al. Sequential daily relations of sleep, pain intensity and attention to pain among women with fibromyalgia. Pain. 1996;68:363-368.

51. Sorbi MJ, Honkoop PC, Godaert GLR. A signal-contingent computer diary for the assessment of psychological precedents of the migraine attack. In: Fahrenberg J, Myrtek M, eds. Ambulatory Assessment. Computer Assisted Psychological and Psychophysiological Methods in Monitoring and Field Studies. Seattle, WA: Hogrefe \& Huber Publishers; 1996:403-412.

52. Sorbi MJ, Honkoop PC, Pos EH. Computer diary as a diagnostic tool in migraine. In: Sorbi MJ, Couturier EGM, Cull RE, eds. Headache and Migraine. Utrecht: Anglo Dutch Migraine Association; 2002:55-64.

53. Sorbi MJ, Honkoop PC, Spierings ELH, et al. A computer-diary based analysis of the International Headache Society classification of migraine. In: Cronicle E, Couturier EGM, eds. Headache and Migraine. Anglo Dutch Migraine Association; 2000:7-14.

54. Honkoop PC, Sorbi MJ, Godaert GLR, et al. High density assessment of the IHS classification criteria for migraine without aura: a prospective study. Cephalalgia. 1999;19:201-206.

55. Sorbi MJ. ODA 1.0. Generic and Interactive Software Application for Electronic Momentary Assessment and Coaching. Utrecht: Utrecht University; 2004

56. Gorin AA, Stone AA. Recall biases and cognitive errors in retrospective self-reports: a call for momentary assessments. In: Baum A, Revenson T, Singer J, eds. Handbook of Health Psychology. Hillsdale, NJ: Erlbaum; 2001:405-413.

57. Fahrenberg J. Ambulatory assessment: issues and perspectives. In: Fahrenberg J, Myrtek M, eds. Ambulatory Assessment. Toronto: Hogrefe and Huber; 1996:3-20. 
58. Stone AA, Shiffman SS, Schwartz JE, et al. Patient non-compliance with paper-diaries. Br Med J. 2002;324:1193-1194.

59. Stone AA, Broderik JE, Schwartz JE, et al. Intensive momentary reporting of pain with an electronic diary: reactivity, compliance and patient satisfaction. Pain. 2003;104:343-351.

60. Jamison RN, Raymond SA, Levine JG, et al. Electronic diaries for monitoring chronic pain: 1-year validation study. Pain. 2001;91:277-285.

61. Stone AA, Shiffman SS, Schwartz JE, et al. Patient compliance with paper and electronic diaries. Control Clin Trials. 2003;24:182-199.

62. Jamison RN, Gracely RH, Raymond SA, et al. Comparative study of electronic vs, paper VAS ratings: a randomized, crossover trial using healthy volunteers. Pain. 2002;99:341-347.

63. Stone AA, Broderik JE, Shiffman SS, et al. Understanding recall of weekly pain from a momentary assessment perspective: absolute agreement, between- and within-person consistency, and judged change in weekly pain. Pain. 2004;107:61-69.

64. Tennen H, Affleck G. Daily processes in coping with chronic pain: methods and analytic strategies. In: Zeidner M, Endler N, eds. Handbook of Coping. New York, NY: Wiley; 1996:151-180.

65. Keefe FJ, Affleck G, France CR, et al. Gender differences in pain, coping, and mood in individuals having osteoarthritic knee pain: a within-day analysis. Pain. 2004;110:571-577.

66. Turner JA, Mancl L, Aaron LA. Pain-related catastrophizing: a daily process study. Pain. 2004;110:103-111.

67. Kerssens JJ, Verhaak PFM, Bartelds AIM, et al. The epidemiology of chronic benign pain disorders in general practice. Eur J Pain. 2002;6:203-212.

68. Peters ML, Sorbi MJ, Kruise DK, et al. Electronic diary assessment of pain, disability and psychological adaptation in patients differing in duration of pain. Pain. 2000;84:181-192.

69. Kerns RD, Turk DC, Rudy TE. The West Haven Yale Multidimensional Pain Inventory (WHYMPI). Pain. 1985;20:345-356.

70. Flor H, Rudy TE, Streit B, et al. Zur anwendbarkeit des West Haven-Yale Multidimensional Pain Inventory im Deutschen Sprachraum. Schmerz. $1991 ; 4: 82-87$.

71. Lousberg R, Groenman NH. De Multidimensional Pain InventoryDutch Version. Lisse: Swets \& Zeitlinger Publishers; 1993.

72. Lousberg R, van Breukelen GJP, Groenman NH, et al. Psychometric properties of the Multidimensional Pain Inventory, Dutch language version (MPI-DLV). Behav Res Ther. 1999;37:167-182.

73. Lousberg R, Schmidt AJM, Groenman NH, et al. Validating the MPIDLV using experience sampling data. J Behav Med. 1997;20:195-206.

74. Kori SH, Miller RP, Todd DD. Kinesophobia: a new view of chronic pain behavior. Pain Manage. 1990:35-43

75. Vlaeyen JWS, Kole Snijders AMJ, Boeren RGB, et al. Fear of movement/reinjury in chronic low back pain and its relation to behavioral performance. Pain. 1995;62:363-372.

76. Rosenstiel A, Keefe FJ. The use of coping strategies in low back pain patients: relationship to patients characteristics and current adjustment. Pain. 1983;17:33-44

77. Spinhoven P, ter Kuile KMM, Linssen ACG, et al. Pain-coping strategies in a Dutch population of chronic low back pain patients. Pain. 1989; 37:77-83.

78. Vlaeyen JWS. Chronic low back pain [dissertation]. University of Maastricht; 1991; Maastricht, The Netherlands.

79. Affleck G, Tennen H, Urrows S, et al. Individual differences in the dayto-day experience of chronic pain: a prospective study of rheumatoid arthritis patients. Health Psychol. 1991;10:419-426.

80. von Baeyer C, White CL, LeFort SM, et al. Reactive effects of measurement of pain. Clin J Pain. 1994;10:18-21.

81. Cruise CE, Broderick J, Porter L, et al. Reactive effects of diary self-assessment in chronic pain patients. Pain. 1996;67:253-258.

82. Kerns RD, Finn P, Haythornthwaite J. Self-monitoring pain intensity: psychometric properties and clinical utility. J Behav Med. 1988;11:71-82.
83. Erskine A, Morley S, Pearce S. Memory for pain: a review. Pain. 1990:155-265.

84. Hox JJ. Multilevel Analysis of Regression and Structural Equation Models. Hillsdale, NJ: Erlbaum; 2002.

85. Snijders TAB, Bosker RJ. Multilevel Analysis. An Introduction to Basic and Advanced Multilevel Modelling. London: Sage Publications Inc; 1992.

86. Wilhelm P. A multilevel approach to analyze ambulatory assessment data: an examination of family members' emotional states in daily life. In: Fahrenberg J, Myrtek M, eds. Progress in Ambulatory Assessment. Computer Assisted Psychological and Psychophysiological Methods in Monitoring and Field Studies. Seattle, WA: Hogrefe \& Huber Publishers; 2001:173-189.

87. Schwartz JE, Stone AA. Strategies for analysing ecological momentary assessment data. Health Psychol. 1998;17:6-16.

88. Raudenbusch SW, Brennan RT, Barnett RC. A multivariate hierarchical model for studying psychological change within married couples. J Fam Psychol. 1995;9:161-171.

89. Langford IH, Bentham G, McDonald AL. Multi-level modelling of geographically aggregated health data: a case study on malignant melanoma mortality and UV exposure in the European Community. Stat Med. 1998;17:41-57.

90. Snijders TAB, Kenny DA. The social relations model for family data: a multi-level approach. Pers Relatsh. 1999;6:471-486.

91. Rasbash J, Browne W, Goldstein H, et al. A User's Guide to MLwiN. Multilevel Models Project. London: London Institute of Education, University of London; 2000 .

92. Bryk AS, Raudenbusch SW. Hierarchical Linear Models: Applications and Data Analysis Methods. London: Sage Publications Inc; 1992.

93. Jamison RN, Brown GK. Validation of hourly pain intensity profiles with chronic pain patients. Pain. 1991;45:123-128

94. de Wit R, van Dam F, Hanneman M, et al. Evaluation of the use of a pain diary in chronic cancer pain patients at home. Pain. 1999;79: 89-99.

95. Hunfeld JA, Perquin CW, Duivenvoorden HJ, et al. Chronic pain and its impact on quality of life in adolescents and their families. $J$ Pediatr Psychol. 2001;26:145-153.

96. van den Brink M, Bandell-Hoekstra EN, Abu-Saad HH. The occurrence of recall bias in pediatric headache: a comparison of questionnaire and diary data. Headache. 2001;41:11-20.

97. Smith WB, Safer MA. Effects of present pain level on recall of chronic pain and medication use. Pain. 1993;55:355-361.

98. Romano JM, Turner JA, Friedman LS, et al. Observational assessment of chronic pain patient-spouse behavioral interactions. Behav Ther 1991;22:549-567.

99. Turk DC, Okifuji A. Evaluating the role of physical, operant, cognitive and affective factors in the pain behavior of chronic pain patients. Behav Modif. 1997;21:259-280.

100. Turk DC, Okifuji A. Assessment of patients' reporting of pain: an integrated perspective. Lancet. 1999;353:1784-1788.

101. Chapman RC, Gavrin J. Suffering: the contribution of persistent pain. Lancet. 1999;353:2233-2236.

102. Editorial. Improving pain management for older adults: an urgent agenda for the educator, investigator and practitioner. Pain. 2002;97:1-4

103. McCracken LM, Eccleston C. Coping or acceptance: what to do about chronic pain? Pain. 2003;105:197-204.

104. Boersma K, Linton S, Overmeer T, et al. Lowering fear-avoidance and enhancing function through exposure in vivo. A multiple baseline study across six patients with back pain. Pain. 2004;108:8-16.

105. Dehghani M, Sharpe L, Nicholas MK. Modification of attentional bias in chronic pain patients: a preliminary study. Eur J Pain. 2004 In press. 